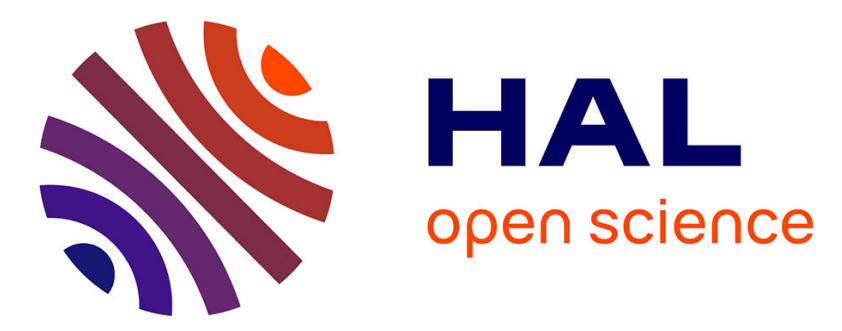

\title{
HOW TO COMPARE BUNDLES OF NATIONAL ENVIRONMENTAL AND DEVELOPMENT INDEXES?
}

Pierre Mazzega, C. Lajaunie, Jimmy Leblet, A F Barros-Platiau, Ch Chansardon

\section{To cite this version:}

Pierre Mazzega, C. Lajaunie, Jimmy Leblet, A F Barros-Platiau, Ch Chansardon. HOW TO COMPARE BUNDLES OF NATIONAL ENVIRONMENTAL AND DEVELOPMENT INDEXES?. Law, Public Policies and Complex Systems: Networks in Action. Law, Gov. \& Tech. Series 16, Springer, 2019. hal-03099962

\section{HAL Id: hal-03099962 https://hal.science/hal-03099962}

Submitted on 4 Jan 2022

HAL is a multi-disciplinary open access archive for the deposit and dissemination of scientific research documents, whether they are published or not. The documents may come from teaching and research institutions in France or abroad, or from public or private research centers.
L'archive ouverte pluridisciplinaire HAL, est destinée au dépôt et à la diffusion de documents scientifiques de niveau recherche, publiés ou non, émanant des établissements d'enseignement et de recherche français ou étrangers, des laboratoires publics ou privés. 


\title{
Chapter 12. How to Compare Bundles of National ENVIRONMENTAL AND DEVELOPMENT INDEXES?
}

\section{Pierre Mazzega, Claire Lajaunie, Jimmy Leblet, Ana Flavia Barros- Platiau and Charles Chansardon}

P. Mazzega (corresponding author)

UMR5563 GET Geosciences Environment Toulouse, CNRS / University of Toulouse, France; Affiliate Researcher SCELG Strathclyde Centre for Environmental Law \& Governance, University of Strathclyde, Glasgow, Scotland

e-mail: pierre.mazzegaciamp@get.omp.eu

\section{Lajaunie}

INSERM, CERIC, UMR DICE 7318, CNRS, Aix Marseille Univ., Univ. of Toulon, Univ. Pau \& Pays Adour, France; Affiliate Researcher SCELG Strathclyde Centre for Environmental Law \& Governance, University of Strathclyde, Glasgow, Scotland

e-mail: claire.lajaunie@inserm.fr

J. Leblet

University of Lyon, Jean Moulin, iaelyon, Magellan Research Center, Lyon, France e-mail: jimmy.leblet@univ-lyon3.fr

\author{
A. F. Barros-Platiau \\ IREL, Institute of International Relations, University of Brasilia, Brasilia DF, Brazil \\ e-mail: anabarros@unb.br
}

\section{Ch. Chansardon}

UMR5563 GET Geosciences Environment Toulouse, CNRS / University of Toulouse, France e-mail: charles.chansardon@ get.omp.fr

\begin{abstract}
This study intends to demonstrate the value of using the partial order set theory comparing different but intertwined sets of indicators or indexes. We illustrate this approach by analysing the relative positions (partial order) of a set of countries with consideration for environmental and development indicators. Using data from 2013, the analysis mainly covers the countries with economies having a strong impact on climate change - China, the USA, the European Union (member States), India, Russian Federation, Japan, Brazil, Canada, and Mexico. The concepts of total and partial orders, linear extension or comparability are introduced and used in the analysis. The inclusion of three integrative environmental indicators and two development indicators (human development index and GDP per capita) shows that in 2013 the BRICS were the worst positioned countries. In contrast, several countries in Northern Europe (Denmark, followed by Germany, Ireland, the Netherlands, Sweden and the UK) were associated with the best overall indicators. Canada is not comparable to any other country, the values of its indicators being sometimes higher and sometimes lower than those associated to any other country considered in this study. The USA, comparable to a single country, shows a similar behaviour for the same reasons.
\end{abstract}


Keywords. Indicators, environment, development, partial order set, national rank, Europe, BRICS, climate powers.

\subsection{INTRODUCTION}

This study is to some extent at the junction of the interests of several disciplines that can be identified at least from the background of the authors (modelling, law, mathematics, international relations, environmental sciences). Thus, we do not deal here with the definitions underlying the use of terms such as "development", "sustainable development", "environment", terms with a broad and rather blurred semantic and pragmatic basis. On the other hand, we highlight the mathematical structure induced by the simultaneous comparison of several indicators and introduce some notions allowing a rigorous analysis to address the issue at hand, in an innovative way, apparently never used in this context.

As stated by Hammond et al. (1995), an indicator is "something that provides a clue to a matter of larger significance or makes perceptible a trend or phenomenon that is not immediately detectable"145. In this vein, the notion of environmental indicator has been promoted after the United Nations Conference on Environment and Development ${ }^{146}$ in 1992 which put the sustainability goal at the core of international considerations together with environmental issues. Indeed, sustainable development calls for a balance between economic growth, social equity and environmental management which may involve rather complex issues, such as economic and social interconnectedness.

There are various kinds of indicators and their choice depends on the goals to pursue as well as the audience targeted (international or national decision-makers, stakeholders or the public opinion). The selection of the appropriate indicators is crucial for policy-makers and the process of indicator selection itself should be scrutinized to make sure it provides the relevant information. The choice of indicators can generate difficulties and biases (Meadows, 1998) ${ }^{147}$. Also, the creation of indicators relies on high quality data and raises the question of the geographical scale chosen (local, national, regional or global). Many questions arise from the elaboration of environmental indicators which can be used at the global level from the scale used, to the type of aggregation or the consideration of time, limit or thresholds ${ }^{148}$. Some of the indicators or indexes are aggregated indicators as they gather diverse measures to give a better overview of a situation (e.g. the Human Development Index, HDI, see below). Others, - such as the Gross Domestic Product, GDP - are developed on the basis of relatively homogeneous data, should they come from the same topic area (e.g. economy), or the data used to build the indicator being expressed in a single unit (e.g. a currency like the US dollar).

After the 1992 Rio Summit, in order to assess the implementation of development policies and to inform policy-makers, the Commission on Sustainable Development was created and various indicators were produced mostly by international organizations, research centres and NGOs. However, to assess the wide-range of impacts of human activities on the environment, it became necessary to think about a framework for environmental indicators to structure sets of environmental information, to make them accessible to policy-makers, to raise public awareness and thus foster public action. At the international level, indicators are also used to report progress in the implementation of policies or commitments of the States before international organizations such as the United Nations or to compare the trends of progress of various countries regarding specific areas such as environmental management

\footnotetext{
${ }^{145}$ In Hammond et al., 1995, p. 1.

${ }^{146}$ See http://www.un.org/geninfo/bp/enviro.html (accessed 20 July, 2018)

${ }^{147}$ In Meadows, 1998,p. 4-5.

${ }^{148}$ Meadows, 1998, p. 12.
} 
and development strategies. One good case is the transition to a low carbon economy now going on in several countries ${ }^{149}$.

Two warnings about the perimeter of this study must be given in this introduction. First, we do not propose an analysis of the relevance of the indicators (in general or those we use here), nor a critique of how these indicators are conceived, developed or used. However, it is important to differentiate between "indicators" and "data" that are system state variables that are empirically observed or measured (instrument measurements, survey results). The main differences reside in the three following points: 1) an indicator in general results from the composition of several empirical data or derived products of different kinds; 2) the method of composition is explicit but relatively arbitrary; it is based mainly on the knowledge of experts in a field and on their estimation that the indicator developed provides relevant and reliable information on the aggregated properties of interest to the expected users; 3) Most indicators are published without an estimate of their accuracy or associated confidence intervals. The production of this estimate is feasible (taking into account the error distributions associated with each component of the indicator and the way in which these components are used) by those who produce the indicators, but not a posteriori by the end-users.

Secondly, an analysis of the relevance of these indicators or of the areas to which they refer (here development, environment, environmental performance), goes far beyond the scope of this paper as well as the intent of our study. There is a priori no objective criterion for the relevance of an indicator in any field of study. An indicator is added to the instruments of a system's governance if its shared use is gradually imposed by dissemination among the organizations concerned. Moreover, the delimitation of the semantic field associated by a diversity of actors with a notion as broad and versatile as "environmental performance" is a political matter and if necessary stabilizes only in duration and by use. This is even more true of the notion of "development" which has been and is the subject of many analyses and criticisms (e. g. with different perspectives and 15 years of delay, Rist, 2001; Monebhurrun, 2016, and references cited in these works), or the notion of "sustainability" (e. g. Ness et al., 2007). More specifically, debates on the Millennium Development Goals (Fehling et al., 2013), and on the new Sustainable Development Goals and indicators to be constructed to assess the achievement of evidence-based targets (ICSU ISSC, 2015) will not be discussed here. Nevertheless, the mathematical structure underlying the comparison of a bundle of indicators will necessarily be the same as that presented here, whatever the context.

It should be stressed that this mathematical structure (of partial ordered sets) necessarily results from the comparison of sets of indicators and is not an optional choice of analysis method. To our knowledge this analysis of sets of indicators has never been proposed before (though, as we shall see in the discussion, it has connections with the theory of voting).

To compare bundles of environmental and development given indexes, we will focus on national indicators. Indeed, at the national level, indicators are designed for and used in supporting decisionmaking, serving the monitoring and evaluation of national policies effectiveness or guiding the identification of priorities for action. Our goal is to define a method that allows comparing the relative positioning of various countries regarding different socio-economic and environmental indicators considered simultaneously. In Section 12.2, we present indicators used in this study and explain the choice of countries we have made. Their consideration leads to a structure of partial order presented in Section 12.3 where we also introduce notions of linear extension, height and width of orders as well as comparability between countries. The use of this approach is illustrated in Section 12.4 by the presentation of three partial orders induced by the respective integration of two socio-economic indicators and three environmental indicators or indexes, and finally the five indicators considered

\footnotetext{
${ }^{149}$ Conscious Uncoupling? Low Carbon Economy Index, 2015. www.pwc.co.uk/sustainability, accessed 20 July, 2018.
} 
simultaneously. The analysis of results in Section 12.5 gives us the opportunity to discuss about the interest and potential of the method. We finally present our conclusions in Section 12.6.

\subsection{SOME DEVELOPMENT AND ENVIRONMENTAL INDICATORS}

The assessment of the evolution of the various components of the environment -mainly ecosystems and resources or media like air, water or soil for instance - but also the evaluation of the efforts undertaken by the countries to conduct public policies and develop legal tools targeting the protection or restoration of ecosystems and the sustainable management of resources, are supported by environmental indicators. The comparison of those indicators among countries is interesting in itself but it might be useful to take into account other indicators of social or economic development. The priority given to environmental agenda over other socio-economic challenges depends on the level of development of each country, whatever definition of development we consider. We only take into account national indicators and to maintain a temporal consistency, we have gathered the values of those indicators for the year 2013. Table 12.1 presents a list of the chosen indicators and the links to the databases where values for that year are available.

Table 12.1 List of indicators used, and links to databases (year 2013)

\begin{tabular}{|c|l|l|}
\hline Acronym & \multicolumn{1}{|c|}{ Index } & \multicolumn{1}{c|}{ Source and Link to Data } \\
\hline \hline EPI & $\begin{array}{l}\text { Environmental } \\
\text { Performance Index }\end{array}$ & $\begin{array}{l}\text { Yale University } \\
\text { http://epi.yale.edu/ }\end{array}$ \\
\hline CCPI & $\begin{array}{l}\text { Climate Change } \\
\text { Performance Index }\end{array}$ & $\begin{array}{l}\text { Germanwatch } \\
\text { http://germanwatch.org/en/home }\end{array}$ \\
\hline CLIMI & $\begin{array}{l}\text { Climate Laws, } \\
\text { Institutions \& \& } \\
\text { Measures Index }\end{array}$ & $\begin{array}{l}\text { Smith School of Enterprise and the Environment } \\
\text { www.smithschool.ox.ac.uk/ }\end{array}$ \\
\hline HDI & $\begin{array}{l}\text { Human } \\
\text { Development Index }\end{array}$ & $\begin{array}{l}\text { United Nations Development Program } \\
\text { http://hdr.undp.org/en/content/human-development-index-hdi }\end{array}$ \\
\hline GDP/cap & $\begin{array}{l}\text { Gross Domestic } \\
\text { Product per Capita }\end{array}$ & $\begin{array}{l}\text { World Bank } \\
\text { http://data.worldbank.org/indicator/ }\end{array}$ \\
\hline
\end{tabular}

At present, teams producing different indicators are working without real coordination ${ }^{150}$. This situation leads to indicators whose statistical independence is difficult to assess. This is all the more true given that the data included in the composition of the various indicators may be of different types but not themselves independent ${ }^{151}$. A priori the indicators used here could induce a form of overweight of climate performances (through CCPI and CLIMI indicators, see below) and thus create a bias in favour of countries with effective and efficient climate policies. On the other hand, the number of environmental indicators available for a large number of countries and the same year (without speaking yet about time series of indicators) is quite limited and justifies our choice. Those used here are covering a large range of information on the environment, law and policies. We now give a brief description of development (Sub-sec. 12.2.1) and environmental (Sub-sec. 12.2.2) indicators or indexes, and then explain our choice of a set of countries (Sub-sec. 12.2.3).

\footnotetext{
${ }^{150}$ The international diffusion of SDGs, anticipated in recent years, probably catalyses efforts - particularly national ones - in this rapidly evolving field of research.

${ }^{151}$ Consider, for example, the various products providing information on environmental variables but derived on the basis of data obtained from the same sensors on board satellites and corrected according to the same standardized procedures (and themselves based on models with a limited accuracy).
} 


\subsubsection{Indexes of Development}

Conventionally, the Gross Domestic Product (GDP) measures the value of all final goods and services produced in a given country in one year. It can be seen as an estimate of the health of a country's economy and national development level that can be compared across countries using the Purchase Power Parity dollar, ie an exchange rate currency. Its evaluation is based on two main approaches that should give very similar results ${ }^{152}: 1$ ) in the income approach, GDP adds up total compensation to employees, gross profits for firms, and taxes less any subsidies; 2) in the expenditure method GDP is calculated by adding total consumption, investment, government spending and net exports. The data used here are obtained from the web site of the World Bank ${ }^{153}$. For year 2013, the top-ten countries of your set, rank as follows (numbers in parentheses are GDP in Billions USD) : 1) USA (16525,593); 2) China (8000,516); 3) Japan (6080,705); 4) Germany (3546,635); 5) France (2750,544); 6) UK (2617,375); 7) Brazil (2471,485); 8) Italy (2166,696); 9)Russian Federation (2068,772); 10) India $(1955,181)$. In 2013, China's population accounted for $\sim 19 \%$ of the world population, and India's for $17.5 \%$. Therefore, to get an idea of economic welfare at the individual level, and incorporate this information into a comparison with environmental indexes, it is better to rely on the GDP per capita which figures are given in Table 12.2. The resulting order brings up countries from Northern Europe along with the USA, Canada and Japan.

Table 12.2 Top ten countries as ranked by each indicator or index, year 2013. Note that Luxembourg is ranked 1st for EPI (83.29) and GDP/cap (109,715 USD) but is not kept in our study. Indicators values (in parentheses) are dimensionless (except the GDP/cap in USD)

\begin{tabular}{|c|c|c|c|c|c|}
\hline Rank & EPI & CCPI & CLIMI & $\begin{array}{c}\text { GDP/cap } \\
\text { (USD) }\end{array}$ & HDI \\
\hline \hline 1 & $\begin{array}{c}\text { Czech Rep. } \\
(81.47)\end{array}$ & $\begin{array}{c}\text { Denmark } \\
(72,61)\end{array}$ & $\begin{array}{c}\text { UK } \\
(0,801)\end{array}$ & $\begin{array}{c}\text { Denmark } \\
(60,368)\end{array}$ & $\begin{array}{c}\text { Netherlands } \\
(0,915)\end{array}$ \\
\hline 2 & $\begin{array}{c}\text { Germany } \\
(80.47)\end{array}$ & $\begin{array}{c}\text { Sweden } \\
(69,37)\end{array}$ & $\begin{array}{c}\text { Finland } \\
(0,787)\end{array}$ & $\begin{array}{c}\text { Sweden } \\
(56,754)\end{array}$ & $\begin{array}{c}\text { USA } \\
(0,914)\end{array}$ \\
\hline 3 & Spain & Portugal & $\begin{array}{c}\text { France } \\
(67,81)\end{array}$ & $\begin{array}{c}\text { USA } \\
(0,783)\end{array}$ & $\begin{array}{c}\text { Germany } \\
(0,911)\end{array}$ \\
\hline 4 & Austria & Germany & Spain & Canada & Canada \\
& $(78.32)$ & $(67,54)$ & $(0,758)$ & $(50,133)$ & $(0,902)$ \\
\hline 5 & Sweden & Ireland & Denmark & Ireland & Denmark \\
& $(78.09)$ & $(67,48)$ & $(0,722)$ & $(48,631)$ & $(0,900)$ \\
\hline 6 & Netherlands & UK & Sweden & Netherlands & Ireland \\
& $(77.75)$ & $(67,33)$ & $(0,701)$ & $(48,190)$ & $(0,899)$ \\
\hline 7 & UK & Malta & Slovenia & Japan & Sweden \\
& $(77.35)$ & $(67,07)$ & $(0,698)$ & $(47,752)$ & $(0,898)$ \\
\hline 8 & Denmark & Hungary & Netherlands & Finland & UK \\
& $(76.92)$ & $(66,41)$ & $(0,691)$ & $(45,903)$ & $(0,892)$ \\
\hline 9 & Slovenia & Belgium & Ireland & Austria & Korea \\
& $(76.43)$ & $(65,20)$ & $(0,667)$ & $(45,663)$ & $(0,891)$ \\
\hline 10 & Portugal & Mexico & Germany & Belgium & Japan \\
& $(75.80)$ & $(64,91)$ & $(0,665)$ & $(44,710)$ & $(0,890)$ \\
\hline
\end{tabular}

Although GDP is probably the most widely used indicator, various criticisms have been made, including recently in anticipation of the transition from the Millennium Development Goals to the Sustainable Development Goals in 2015 (United Nations, 2016), which mainly point out that other

\footnotetext{
${ }^{152}$ See http://www.investopedia.com/ask/answers/199.asp (accessed 20 July, 2018).

${ }^{153} \mathrm{http}$ ://data.worldbank.org/indicator/NY.GDP.MKTP.CD (accessed 20 July, 2018).
} 
dimensions of development are not taken into account or probed by this indicator to assess the progress and sustainability of our societies. Only considering the special issue "Beyond GDP" of the Human Dimensions magazine (May 2014 issue 4), human well-being (Bartelmus, 2014), human and ecosystems health (Dasgupta, 2014) or natural capital and human capital (Duraiappah and Fernandes, 2014) in particular are nearly invisible through the GDP.

Indeed, the very concept of human development in its relations with various themes such as the environment, gender, globalization, migration, etc. - is the subject of much debate (Alkire, 2010) that results are transferred to the concept of associated evaluation indexes (Kovacevic, 2010). To partially fill the gap left by considering only GDP per capita as an indicator of development, we also include the human development index (HDI). This index, first published by UNDP in 1990 with the Human Development Report (UNDP, 1990), is widely used in particular to capture the multidimensional nature of poverty at the national level. It constitutes an aggregation of three indicators based on health, education and standard of living. It provides a broader measure of human well-being that GDP itself but it is limited as it does not include any information regarding environmental changes. As such it does not appear as an appropriate indicator of the environmental dimensions of development, a gap that is filled precisely by associating environmental indicators in our overall analysis (Sec. 12.4). Among the 10 non-European countries in our sample with the highest HDI index in 2013, we found the USA, Canada, South Korea and Japan (Table 12.2), these countries - except South Korea, also being in the top ten countries with higher GDP per capita.

\subsubsection{Environmental Indicators}

The Agenda 21, one of the instruments resulting from the Rio Conference, states that "indicators of sustainable development need to be developed to provide a solid basis for decision-making at all levels and to contribute to the self-regulating sustainability of integrated environment and development systems" (UNCED, 1992, Chap.40, §4). Several organizations listed environmental issues and corresponding indicators following an initial work from the OECD. The information should be organized according to a matrix of information grouping various categories of environmental issues dealing with human/environment interactions ${ }^{154}$. Here we have chosen three environmental indexes according to the following criteria: a) be available for each of the countries of our list and for the year 2013; b) be informed (identification of the original data allowing their assessment; explanations about their development mode); c) be publicly available on the internet.

The Environmental Performance Index (EPI) is produced by a network of organizations, under the guidance of Yale University ${ }^{155}$.The EPI ranks countries' performance on high-priority environmental issues related to the protection of human health and the protection of ecosystems. In 2013, the EPI was constructed through the calculation and aggregation of 20 indicators reflecting national-level environmental data (Hsu et al., 2013). These indicators are combined into 9 issue categories: environment health impacts, air quality, water and sanitation, water resources, agriculture, forests, fisheries, biodiversity and habitat, climate and energy. The overall EPI framework is fully described, as well as, among others, the selection criteria for data in EPI (say relevance, performance, established scientific methodology, data quality, time series availability, completeness ${ }^{156}$ ). In the subset of 36 countries that we have selected for this study, the top-ten countries ranked on the basis of this index are all European countries, especially from Northern Europe (see Table 12.2).

\footnotetext{
${ }^{154}$ On the development of such matrix, see Hammond et al., 1995, p. 13-16.

155 Say in 2016, the Yale Center for Environmental Law \& Policy and Yale Data-Driven Environmental Solutions Group at Yale University, the Center for International Earth Science Information Network at Columbia University, in collaboration with the Samuel Family Foundation, McCall MacBain Foundation, and the World Economic Forum.

${ }^{156}$ See https://epi.envirocenter.yale.edu/2018-epi-report/methodology (accessed 20 July, 2018)
} 
The Climate Change Performance Index (CCPI) 2013 (Burck et al., 2012) is produced by Germanwatch (Bonn), a nonprofit non-governmental organization in collaboration with the Climate Action Network Europe (CAN, Brussels). Through the evaluation and comparison of the climate protection performances of 58 countries responsible for more than $90 \%$ of the energy-related $\mathrm{CO}_{2}$ global emissions, it is an instrument supposed to enhance transparency in international climate politics. It is primarily centred on objective indicators. Eighty percent of the evaluation is based on indicators of emissions and is decomposed as 30\% for emissions levels, $30 \%$ for recent development of emissions, 5\% level of efficiency, 5\% recent development in efficiency, $8 \%$ recent development of renewable energy and $2 \%$ share of total primary energy supply. The remaining $20 \%$ of the CCPI evaluation is based on national and international climate policy assessments (that involve more than 250 experts from the respective countries) (Burck et al., 2015). Nine of the top-ten countries ranked by this index are European ones, Mexico being at the tenth place (Table 12.2).

The "Climate Laws, Institutions and Measures Index" (CLIMI) evaluates countries' policy responses to the risk of climate change. It measures the breadth and quality of four main policies (12 constituent variables) areas in 95 countries representing $90 \%$ of the global greenhouse gas emissions (Steves and Teytelboym, 2013): 1) the international co-operation: how quickly a government ratified the Kyoto Protocol and whether it developed the institutional capacity to participate in the flexible mechanisms or the Clean Development Mechanism; 2) the domestic climate framework: this includes broad climate change laws and targets, as well as the levels of institutional engagement in climate change; 3)the sectoral fiscal or regulatory measures or targets: these include targets and regulations in each of the sectors identified in the reports of the Intergovernmental Panel on Climate Change, apart from waste; 4) the cross-sectoral fiscal or regulatory measures: these include carbon taxes and emission-trading schemes. CLIMI therefore does not cover several important environmental issues ${ }^{157}$. However this indicator gives a large place to the evaluation of public policies implemented to fight against climate change and mitigate its effects, initiatives that affect large sectors in particular energy policy (see e.g. Jones and Warner, 2016) and the oceans. Once again only European countries are in the top-ten countries ranked with this indicator.

\subsubsection{The Set of Countries}

We have limited our analysis to a list of 36 countries. The inclusion of all United Nations member countries would unnecessarily extend our work which aims primarily to propose a method of analysis and comparison of a set of national indicators and to allow for a partial ordering of the considered countries. Moreover environmental indicators are generally not available for all countries, their assessment requesting numerous data that are often unavailable or with too limited a reliability.

Our interest focuses first on the countries of the European Union (before the 2016 BREXIT). Whether in terms of size of the national territory, population or level of development, these countries offer a contrasted picture. However, their policies and environmental legislations are relatively harmonized (Vogler, 2011), including adherence to the norms produced by the numerous environmental framework directives. The cohesion of their commitment in multilateral environmental agreements through the ratification of the major environmental conventions in particular, has given the European Union and its main economic and strategic partners (USA, Canada, Japan in particular) the leadership in the process of structuring a global environmental order over the past forty years (Boulet et al., 2016a,b). Note, however, that Cyprus and Luxembourg are not included in this analysis because the values of environmental indicators that we have selected (see below) are not available for these countries.

\footnotetext{
${ }^{157}$ Such as the conservation of biodiversity, the sustainable management of marine and ocean resources or health issues in their human, animal and ecosystem dimensions.
} 
Because of their importance as climate powers (Viola and Basso, 2016; Kirton and Kokotsis, 2015) and as drivers of technological innovation and dissemination on the global market, we also consider the USA, Canada, Japan, South Korea and Mexico. In a nutshell, these countries were active players in multilateral negotiations since 1992 regarding environmental and development issues. Not only are they among the world's biggest GHG emitters according to the UNFCCC Secretariat, but their economies are robust and they show potential for the near future to continue on the stage as protagonists related to the transformations in the energy and technology markets.

At the same time China became the biggest greenhouse gas emitter, ahead of the USA and the European Union, it adopted an increasingly ostentatious climate diplomacy, particularly negotiating bilaterally with the US (Shambaugh, 2016). Although they failed to find a consensus on the burden sharing for the Copenhagen Conference of the Parties (CoP 15), they reached an agreement for the CoP 21 in December 2015 and ratified the Paris Agreement during the G20 Summit in Hangzhou this year ${ }^{158}$. Moreover China is part of a political and economic alliance, the BRICS - Brazil, Russian Federation, India, China and South Africa - which includes countries whose economic and development activities have a major impact on the overall balance of emissions (Ge et al., 2014), land use, new infrastructure and biodiversity management. Also, the global energy markets transformations are largely driven by the BRICS (Downie, 2015). The indicator values and ranking of the 10 (or eleven) first countries are given in Table 12.2. Let us briefly present these five indexes or indicators.

\subsection{PARTIAL ORDERS AND BUNDLE OF INDEXES}

A partially ordered set $\mathbf{P}$ (or order) is a set $\mathrm{V}$ with a partial order relation denoted $<$. An order relation is an irreflexive and transitive binary relation. For example, imagine that we have a set of entities $\{\mathrm{A}, \mathrm{B}, \mathrm{C}, \ldots\}$ which we compare the attractiveness. The relation "is less attractive than" is an order relation ${ }^{159}$. Indeed, it is irreflexive - we cannot say that "A is less attractive than $A$ " - and transitive: if " $A$ is less attractive than $B$ " and " $B$ less attractive than $C$ " then we necessarily have that " $A$ is less attractive than $C^{\prime \prime}$. Naturally, an ordered set can be viewed as a transitive directed graph and therefore can be represented graphically.

Indeed, we consider the ordered set with vertices entities A, B, C, D and E in Figure 12.1. The arrow going from $\mathrm{A}$ to $\mathrm{B}$ means that "A is less attractive than $B$ " (or $\mathrm{A}<\mathrm{B}$ ). It may be noted that in this representation, all relationships are not represented. Indeed, relations induced by transitivity are not necessary in the representation and would overload the graph.

Fig. 12.1 Example of a partial order set

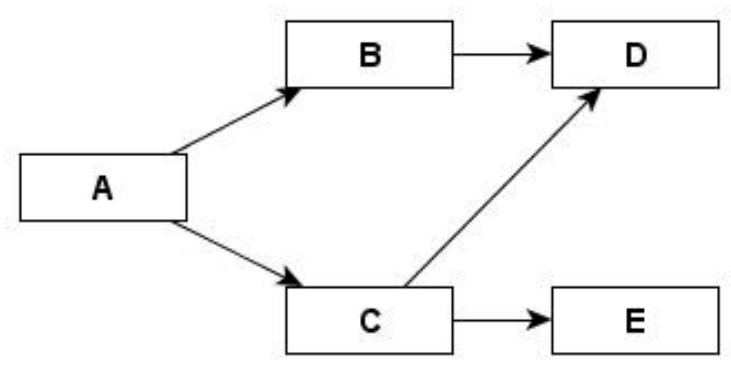

However, the transitive relations actually appear: as we have that " $A$ is less attractive than $B$ " and "B is less attractive than $D$ " by transitivity we get that "A is less attractive than $D$ ". Graphically this means

\footnotetext{
${ }^{158}$ https://treaties.un.org. Accessed 20 July, 2018.

${ }^{159}$ Note that when $\mathrm{A}<\mathrm{B}$ holds, we can say in a general way that $\mathrm{A}$ is smaller than $\mathrm{B}$.
} 
the existence of a directed path (following the arrows) ranging from A to D. Also, there is a directed path from A to $\mathrm{E}$ translating the fact that " $A$ is less attractive than $E "$ ".

Two vertices (or elements) of an ordered set are said to be comparable if a relationship exists between them (that is to say that one is smaller than the other). For example, in Fig. 12.1, A and B are comparable, as well as D and C. Two vertices are said to be incomparable if there is no relationship between them (that is to say that it is not possible to tell if one is "smaller" than the other). In our previous example, D and E are incomparable, as well as B and E. Graphically, two vertices are incomparable if there is no path (following the direction of the arrows) from one to the other. Orders having only elements that are comparable by pairs (i.e. having no incomparability) are called total orders, such as orders in Figure 12.2. The usual orders on integer or real numbers are total orders: they can be ordered fully from the smallest to the largest elements.

The minimal elements of an order are the elements of this order that have no smaller elements. For example, the order in Figure 12.1 has a single minimum which is A. Graphically this corresponds to the vertices of the graph with no arrow arriving at these vertices. Similarly, we can define the maximal elements of an order as the elements having no larger elements in that order. D and $\mathrm{E}$ are the maximal elements in the order of Figure 12.1. Graphically, this corresponds to the elements having no arrow outgoing from the corresponding vertices. The height of a vertex is the maximum length of a path going from a minimum of the order to that vertex. For example, in Figure 12.1, E has a height of 2, A has a height of 0 and $\mathrm{C}$ a height of 1 . The height of an order is the maximum height of its elements. In a dual way, we define the width of an order. The width of an order is the maximum size of a subset of its elements such as all elements of this subset are incomparable two by two. For example, the width of the order of Figure 12.1 is two. Indeed, if we take the set consisting of B and E, we see that these two elements are incomparable.

Then, any combinations consisting of three vertices of the order will have at least two comparable elements, so the width of the order is actually 2 . As a result, a total order with $\mathrm{n}$ components has a height of n-1 and width of one. Conversely, an order with zero heights on $n$ elements is an order in which all elements are incomparable in pairs and has a width of $n$. For further details about partial orders, see Schröder's book (Schröder, 2003).

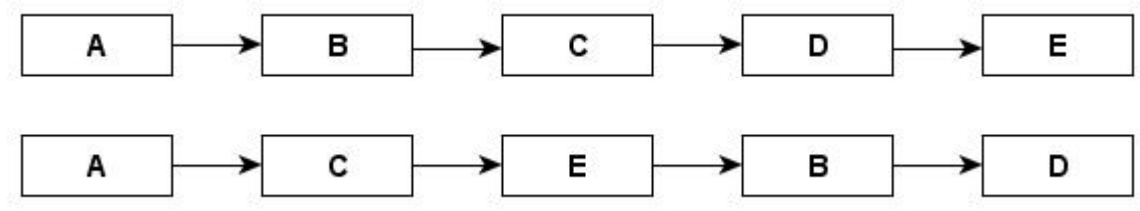

Fig. 12.2 Two distinctive linear extensions of order shown in Fig. 12.1

Given a partial order $\mathbf{P}$, a linear extension $\mathbf{L}$ of this order is a total order on the elements of $\mathbf{P}$ such that each comparability of elements in $\mathbf{P}$ is preserved in $\mathbf{L}$ (that is to say, if a vertex A is smaller than another one, say B, in $\mathbf{P}$ then A must also be smaller than B in $\mathbf{L}$ ). For example, the two total orders shown in Figure 12.2 are linear extensions of the order of Figure 12.1. One question is whether the original order can be found from the linear extensions. First we define the intersection of two linear extensions $\mathbf{L}_{\mathbf{1}}$ and $\mathbf{L}_{2}$ as the partial order $\mathbf{P}$ having the same elements as $\mathbf{L}_{\mathbf{1}}$ and $\mathbf{L}_{\mathbf{2}}$ and such that a vertex is smaller than another in $\mathbf{P}$ if it is also smaller in both $\mathbf{L}_{\mathbf{1}}$ and $\mathbf{L}_{\mathbf{2}}$. The partial order $\mathbf{P}$ is the order that respects all relations $<$ in both $\mathbf{L}_{1}$ and $\mathbf{L}_{2}$. Of course two vertices $A$ and $B$ in $\mathbf{P}$ are incomparable if, for example, we have $\mathrm{A}<\mathrm{B}$ in $\mathbf{L}_{\mathbf{1}}$ and $\mathrm{B}<\mathrm{A}$ in $\mathbf{L}_{\mathbf{2}}$, that is to say, the respective relationships between $\mathrm{A}$ and $\mathrm{B}$ in the two linear extensions are opposed. For example, the intersection of the two linear extensions of Figure 12.2 gives us exactly the partial order in Figure 12.1. We can generalize the intersection to any number of linear extensions: a summit A will be smaller than another 
one $\mathrm{B}$ in the intersection partial order if and only if $\mathrm{A}$ is smaller than $\mathrm{B}$ in all the considered linear extensions. In particular, an order is exactly the intersection of all its linear extensions but it can also be obtained with only a subset of its linear extensions. Note that the intersection of a linear extension and its opposite (linear extension with the reverse order) is an "empty order" ${ }^{160}$ say an order in which all the elements are non-comparable pairs. This shows that just by adding a linear extension to another one can go from a total order (where you can order all elements) to an empty order. For further details about linear extension of partial orders, see Trotter's book (Trotter, 1992).

The five indicators presented in the previous section are linear orders on all the countries concerned and can therefore be seen as linear extensions. The partial order obtained as the intersection of these indicators then allows summarizing the whole of these indexes. Indeed, if a country is smaller than another country in the partial order so obtained, that means it is smaller than this country relatively to all indicators considered. Conversely, if country A is not comparable to country B in the order, it means that there is an indicator for which $\mathrm{A}$ is smaller than $\mathrm{B}(\mathrm{A}<\mathrm{B})$ and there is another indicator showing the opposite, A larger than $\mathrm{B}(\mathrm{A}>\mathrm{B})$.

As stated previously, usually when adding new linear extensions to the construction of the partial order, the more it approaches the "empty" order, that is to say the order where no vertices can be compared two by two. This is the reason why we decided to compose progressively partial orders from our five indicators: a first order made from the socio-economic indicators (HDI and GDP per capita), a second order made from environmental indicators (EPI, CCPI and CLIMI) and the order constituted from the five indicators. In the next section we present and comment the orders obtained.

\subsection{Development And EnVironmental Partial Orders}

Each of the five indicators presented in Section 12.2 defines a total order on the set of selected countries. When we combine several indicators, we consider each of them as a linear extension of a partial order that we rebuild. We now recover three partial orders: the one induced by combining HDI and GDP/capita (Sub-sec. 12.4.1); the one resulting from the combination of the 3 environmental indexes (Sub-sec. 12.4.2) and the one obtained with the 5 indicators (Sub-sec. 12.4.3). The most salient results, i. e. the countries constituting the extremes of the three orders P2, P3 and P5, are presented in Table 12.3.

Table 12.3 Lists of minimal and maximal elements of the three partial orders induced by the 2 development indicators (Figure 12.3), by the 3 environmental indicators (see Figure 12.4), and the 5 indicators taken all together (Figure 12.5)

\begin{tabular}{|l||c|c|}
\hline Partial Order & Minimal Elements & Maximal Elements \\
\hline \hline Development P2 & India & Denmark, Netherlands, USA \\
\hline Environment & Brazil, Canada, China, & Czech Rep., Denmark, Germany, \\
P3 & Russian Fed., India & Spain, Sweden, UK \\
& & \\
\hline Development \& & Brazil, Bulgaria, Canada, & Austria, Canada, Czech Rep., \\
Environment P5 & China, India, Latvia, & Denmark, Finland, France, \\
& Russian Fed., South Africa & Germany, Netherlands, Spain, \\
& \multicolumn{2}{|c}{ Sweden, UK, USA } \\
\hline
\end{tabular}

\footnotetext{
${ }^{160}$ Let us emphasize that an "empty order" is not a set with no elements, but simply that its elements are not comparable in pairs.
} 


\subsubsection{Combining Development Indexes}

The graph corresponding to the partial order obtained by combining the orders induced by the HDI and GDP / capita is shown in Figure 12.3. This partial order - which we denote P2 below - has a height $h=14^{161}$ and a width $w=5$.

Each country is comparable to at least 27 other countries which in a way shows quite a strong consistency of the ranks induced by these two indexes. Indeed, if a country occupies a high rank with an index and on the contrary a very low rank with another index, then it is incomparable to any other country. P2 has a unique smallest element, India, and three maximal elements, USA, Denmark and Netherlands. BRICS occupy the lower ranks, with Mexico, Bulgaria and Romania. USA, Canada and Japan are in the lead group ${ }^{162}$ with several countries from Northern Europe (Denmark, Sweden, Netherlands and Ireland). A second group of some countries with lower ranks, includes Finland, Belgium, Austria, France, the United Kingdom, Slovenia, Italy and Spain. Here is the summary picture of development (economic and human) that provides a simultaneous use of the HDI and GDP per capita.

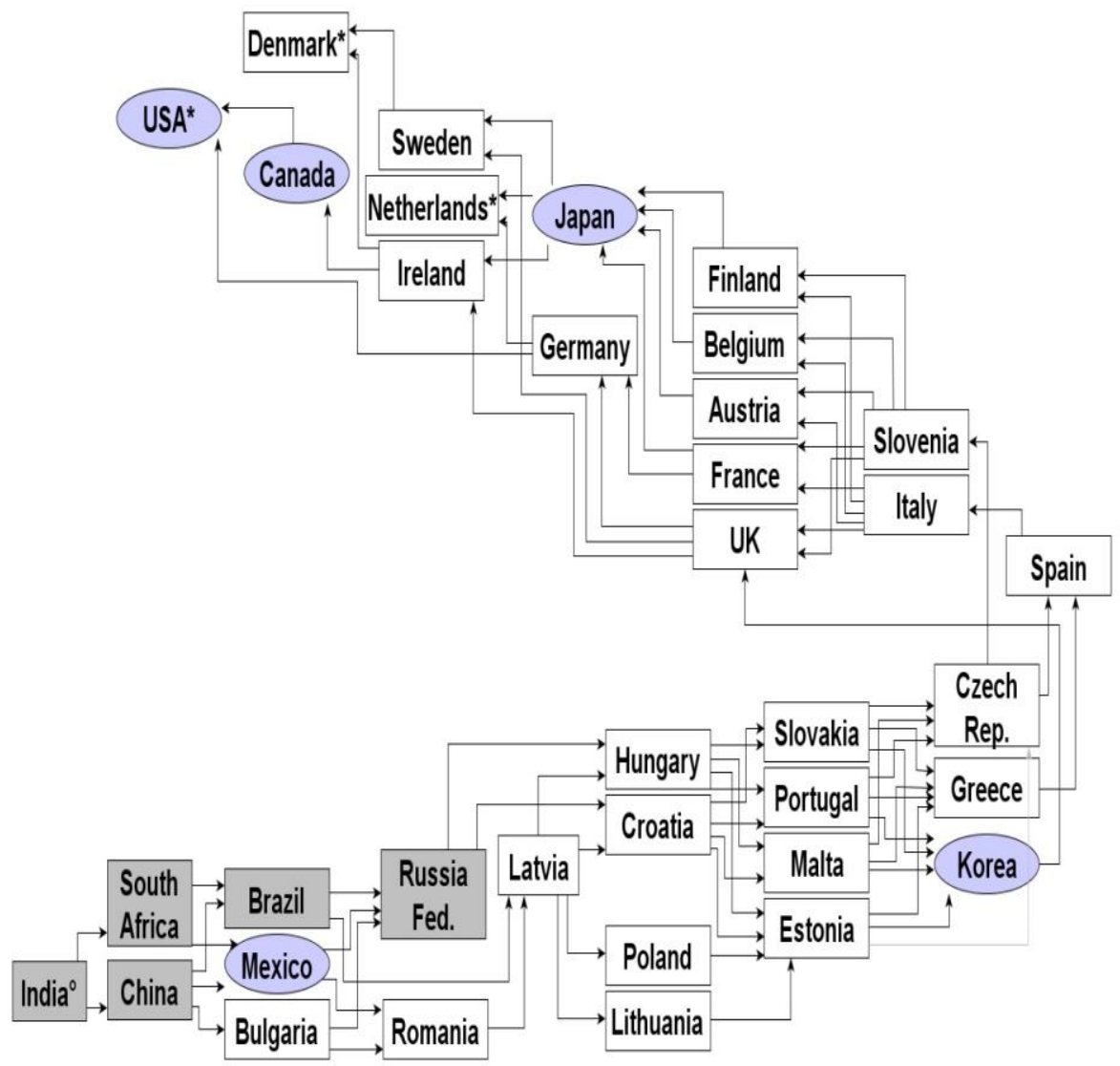

Fig. 12.3 Partial Order P2 induced by the HDI and GDP/capita. The labels of Member States of the EU are in white-rectangles. The BRICS are in grey-rectangles and labels of other countries are in blueellipses. Countries with the best (resp. worse) set of indexes are on the top left-side of the graph (resp. bottom left-side). The label of a maximal (resp. minimal) country is followed by a "*” (resp. a "o")

\footnotetext{
${ }^{161}$ The maximum height of an order with 36 countries is 35 , which would correspond to a total order.

${ }^{162}$ Our use of the term "country group" does not coincide with a class gathering a set of incomparable countries.
} 


\subsubsection{Combining Environmental Indexes}

The relations between countries on the basis of the three environmental indexes show less regular relative positions: the obtained partial order $\mathbf{P 3}$ (see the graph in Figure 12.4) has a much lower height (here $h=5)$ and larger width $(w=12)$ that the previous order.

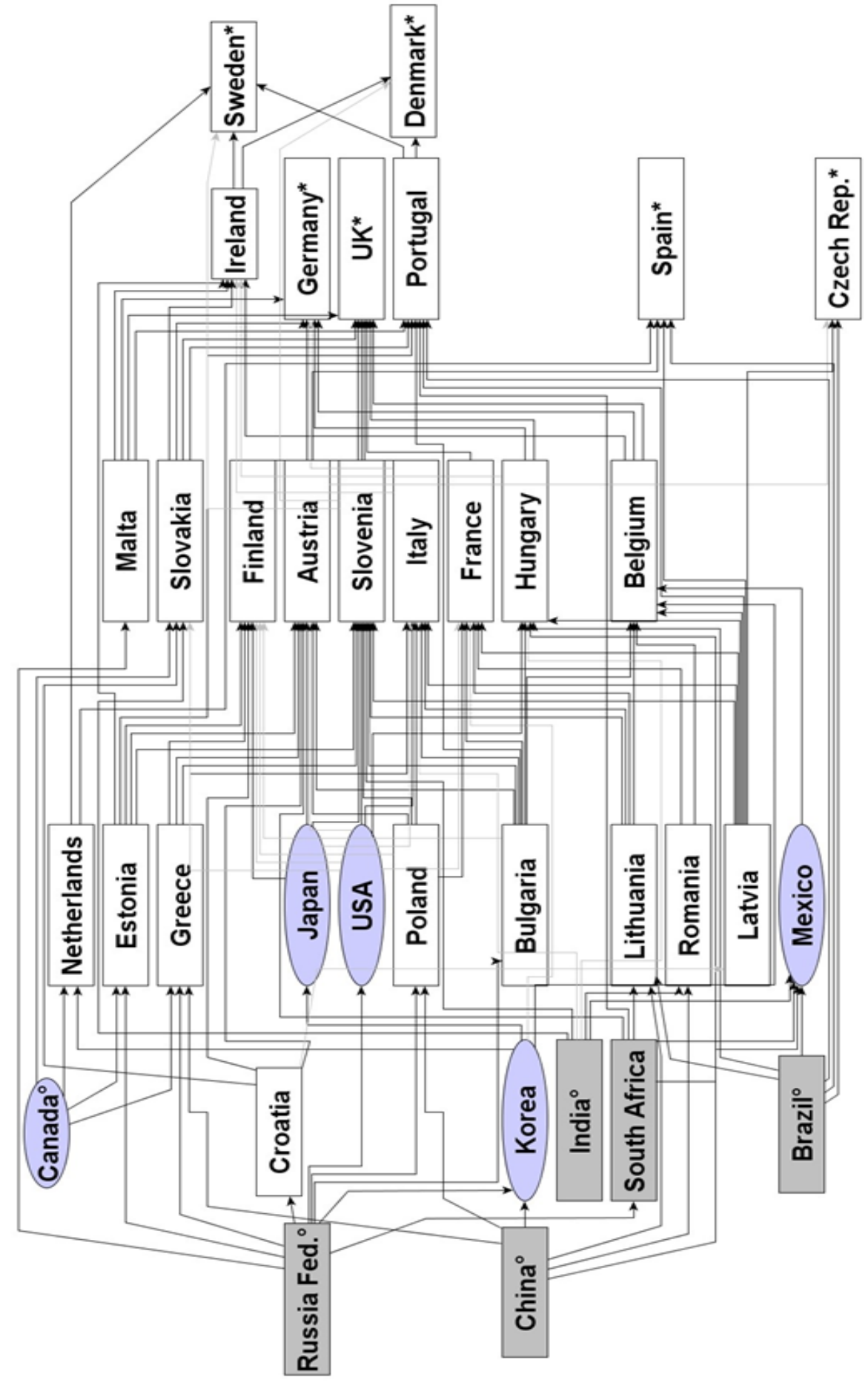

Fig. 12.4 Partial Order P3 induced by the EPI, CCPI and CLIMI environmental indexes. The labels of Member States of the EU are in white-rectangles. The BRICS are in grey-rectangles and labels of other countries are in blue-ellipses. Countries with the best (resp. worse) set of indexes are on the top (resp. bottom) of the graph. The label of a maximal (resp. minimal) country is followed by a "*” (resp. a “o”) 
In other words it is more common that two countries are in reversed positions relative to each other once "larger" and then "smaller" - when two environmental indexes are considered. We obtain five minimal elements - Brazil, Canada, China, India and Russian Federation - and six maximal elements, all European countries - Czech Republic, Denmark, Germany, Spain, Sweden and UK. In 2013 the environmental indexes of Canada, Japan, Mexico, South Korea and USA have lower values than those of most European countries.

Some countries are comparable to many others: the Russian Federation is lower than 30 countries in our set, and at the other end of the partial order - Denmark ( $>26$ countries), Sweden (> 27 countries), UK (> 26 countries), have a high overall environmental quality (including policy and legal initiatives through CLIMI). Comparable to relatively few countries, the results for Mexico (comparable to 11 countries), Malta (comparable to 7 countries) and the Netherlands (comparable to 6 countries) have contrasted environmental performances following the environmental index considered.

\subsubsection{Combining Development and Environmental Indexes}

Combining the development and environmental indexes leads to the partial order P5 shown in Figure 12.5. With a height $h=4$ and a width $w=16$, this order is somewhat flattened. This also results in a high number of both minimal ( 8 vertices with no in-going link: Brazil, Bulgaria, Canada, China, India, Latvia, Russian Federation, South Africa) and maximal (12 vertices with no out-going link: Austria, Canada, Czech Republic, Denmark, Finland, France, Germany, Netherlands, Spain, Sweden, UK, USA) elements. Canada is not comparable to any other country (so it appears as an isolated vertex on the graph, Fig. 12.5; for the same reason it is also both a maximal and a minimal element). This is probably explained by a high ranking on development indicators (4th place on both the GDP per capita and HDI; see Table 12.2), and a position of minimal elements with the environmental indexes. The USA is comparable with one country only (the Russian Federation) for similar reasons. The Netherlands are comparable with 3 other countries. In fact, as we have noted this country is comparable to few other countries if we consider only the environmental indexes and this mixed picture is further enhanced by the inclusion by developing indexes that have high values (6th rank on the GDP / capita and HDI rank 1).

On one side of the partial order P5, Russia and China are comparable to many countries (24 and 21 respectively), and on the other side Denmark, Sweden and Ireland are ranked higher than 24, 23 and 22 countries respectively ${ }^{163}$. However, the most "politically" visible feature is probably the presence of the BRICS at the lowest level of this partial order composed of development indicators and environmental indexes.

\subsection{DISCUSSION}

Once a set of indicators has been chosen to conduct an analysis, the relative position of the countries in the partial order is mathematically defined. In this sense, the method is robust and the results easily reproducible. Each indicator is a linear extension, and their simultaneous consideration induces a partial order, with some countries constituting the maximum and minimum elements and, where appropriate, subsets of other countries being incomparable in pairs. Usually the comparative analyses of the position of the countries, for example, as in this study, according to the developmental or environmental perspectives, are made by considering each indicator in turn and each time modulating the terms of the discourse according to the partial performances of each country. The notion of

\footnotetext{
${ }^{163}$ To know the countries "higher" (resp. "lower") than a country X and their number, just follow on the graph all the paths starting from that country $\mathrm{X}$ following the direction (resp. the inverse direction) of the oriented links, list and count the labels of the vertices encountered.
} 
incomparability is lacking in this type of analysis. Indeed, a subset of countries that are incomparable in consideration of a set of indicators should be considered as a class of countries which is "superior" or "inferior" (in the sense of relations of order) to other subsets of countries. Within such a class, it is in turns a country or another that presents the best indicator values.

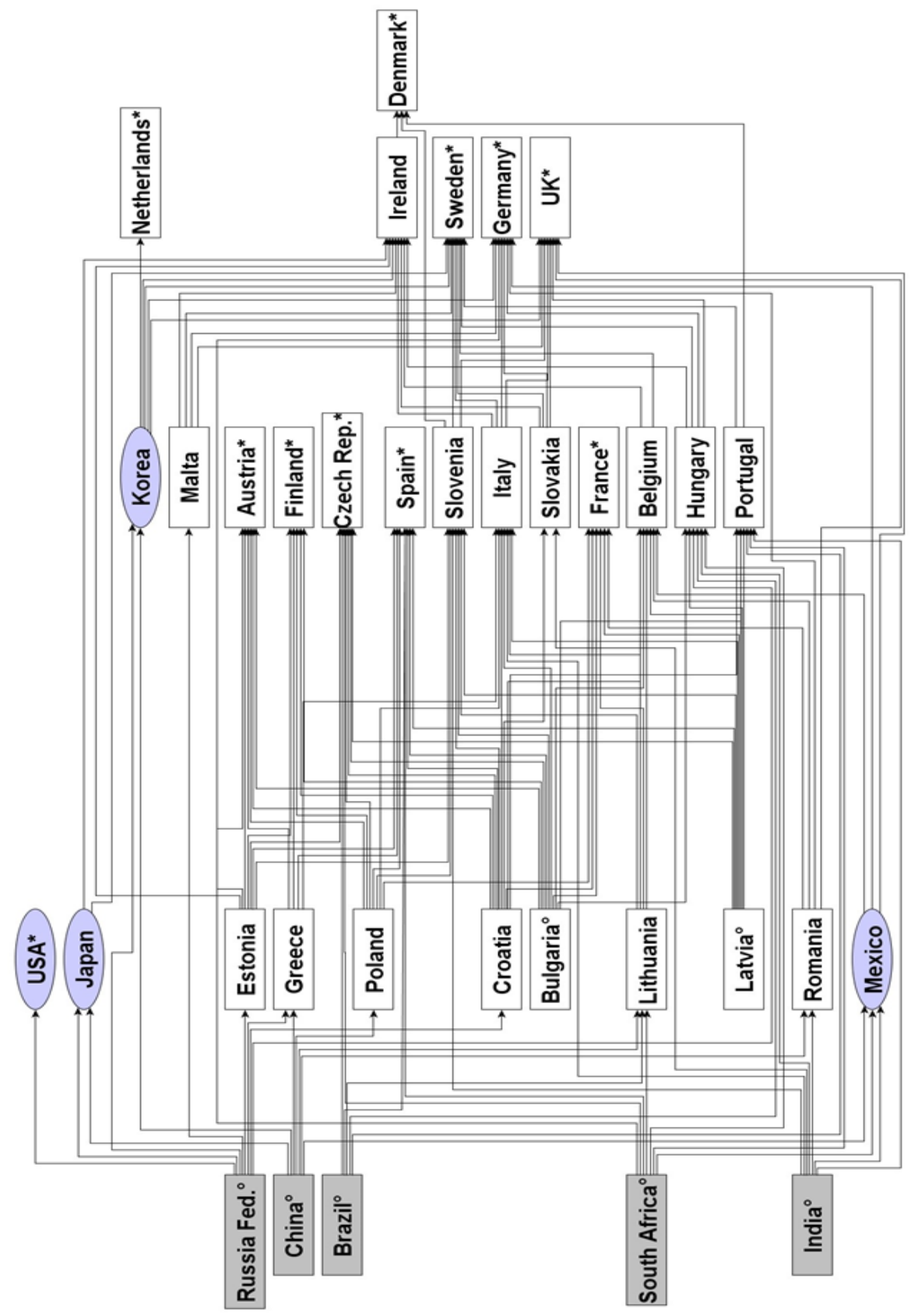

Fig. 12.5 Partial Order P5 induced by five socio-economic and environmental indexes. The labels of Member States of the European Union are in white-rectangles. The BRICS are in grey-rectangles and labels of other countries are in blue-ellipses. Note that Canada being comparable to no other country, it is disconnected from the graph (isolated vertex) and has not been represented. In this figure, countries with the best overall partial ranks are drawn at the top, those with the lowest partial ranks in the bottom. The label of a maximal (resp. minimal) country is followed by a “*” (resp. a "o”)

Note also that a whole body of work derived from the Social Choice Theory could be asked to continue the analysis of groups of indicators if for some reason it was necessary to produce in the end 
a total order of the countries whose performances are compared ${ }^{164}$. Indeed, voting theory was developed as early as the eighteenth century (Condorcet, de Borda) on the basis of some paradoxes like the impossibility of classifying a list of alternatives in a total order from votes casting preferences of each of the voters ( « ranked ballots », in the context of a multi-candidates voting) ${ }^{165}$. Many voting procedures were then proposed to obtain a final order which is necessary for decision-making in the political field, at the cost of abandoning at least one of the "good properties" (every two voters play equivalent roles in our voting rule; every two alternatives are treated equivalently by the rule) of the basic voting conditions (Zwicker, 2016).

The approach using concepts from partial order sets theory is also ideally suited to monitoring the time-evolution of the relative positions of countries, or changes in the composition of groups of two by two incomparable countries. It is also possible to observe the impact of the introduction of a new index (a linear extension) on a partial order of countries ${ }^{166}$, or the effects of the composition of several partial orders as we have done here (composing $\mathbf{P 2}$ and $\mathbf{P 3}$ to produce $\mathbf{P 5}$ ).

This approach can be used to test the robustness of the partial order induced by the aggregate indexes. Another approach is to introduce random perturbations (following a chosen statistical distribution) in the values of one or more indexes. It is quite difficult to draw any dependencies between indexes resulting from a partial recovery of raw data used and even more difficult to assess the impact of these statistical dependencies on partial orders resulting from the composition of the indexes. On the other hand, what would bring an aggregation of the 5 indexes we have used here? A total order indeed, but at the cost of a loss of resolution and information. Thus the interpretation of a partial order is more detailed and relevant if it is also based on the analysis of linear extensions that compose it (here each index considered separately).

In this study, four levels of information processing are actually involved (directly or indirectly): the raw data or derived basic products ${ }^{167}$; the set of sub-indexes or indicators relying on these data sets; the set of indexes (those presented in Sec. 12.2) obtained by aggregation; finally the partial order induced by the composition of the latter. Where do we stop the aggregation of information, and at what level should we use the approach we propose to compose a partial order on the basis of indexes? This reflection echoes the discussion engaged about the congruence between scale of legislation and the scales of the regulated ecosystems to be considered (Lajaunie and Mazzega, 2017). If it does not seem possible to define in a general way an optimal level where to move from an analysis of a set of indexes to that of the partial order they induce (as linear extensions) it is certain that this choice strongly influences the conclusions drawn ${ }^{168}$. Therefore it has to be chosen with scrutiny considering the objectives of the analysis.

The indexes used are necessarily dependent upon matters considered and remains at the discretion of researchers. Although some degree of arbitrariness persists through this choice, conversely we note that the indexes used are designed to be robust and relevant. Indeed, these indexes usually aggregate multiple sub-indexes or indicators (themselves combining via an explicit method many well-identified data which quality is assessed) covering a smaller theme as we have seen in the description of the

\footnotetext{
${ }^{164}$ This need does not exist a priori in the comparative analysis of country performances.

${ }^{165}$ In accordance with certain basic assumptions, this impossibility has been demonstrated mathematically by K. Arrow in 1951, see Saari, 2001.

${ }^{166}$ One can also build scenarios to assess the impact of the improvement of a country index values.

${ }^{167}$ In particular many products are derived from intensive processing of data supplied by sensors on board satellites, and are used to monitor multi-scales environmental changes (land use and land cover, sea level, atmospheric composition, etc.).

${ }^{168}$ Note that the simple aggregation of indices, producing a total order, reduces even more sharply - crushes somehow - the analysis space.
} 
indexes in Section 12.2. It is therefore possible to replace an aggregate index for all the component indicators ${ }^{169}$ and see how the resulting partial orders differ.

Concerning the choice of the indexes, the GINI index ${ }^{170}$ (though not used here) deserves some comments. It was probably the one most used by researchers in social sciences and humanities in the last two decades, but curiously it was not taken into account by diplomats and law-makers in the main multilateral negotiations since 1992. If it were, countries showing a high level of social disparity would be comparable in a specific arena, for example, climate change. Then the North-South cleavage would make more sense, and so would the Kuznet's curve ${ }^{171}$ and its limits. Also, it would be clearer that such a cleavage will persist because Southern countries have development, taken as poverty eradication, as their national priority ${ }^{172}$ and they insist that environmental issues cannot be treated separately from the social agenda. As a consequence, international environmental commitments and compliance to international law make more sense if social vulnerability and interconnectedness, as well as risk management capacities of given countries are taken into account. In other words, social disparity makes it is harder for national public authorities to comply with international environmental obligations because constituency is far more heterogeneous. As strange as it may seem, it is the case of Greece right now. On the other hand, if we take indicators about technology and investments related to economic decarbonization then it makes no longer sense to put China in the BRICS, because it is more comparable to the US and the EU. In this sense, indicators are not new, but they lead to different results and may be useful for decision-makers seeking to deal with sustainable development issues, so they were used more frequently since 1992.

\subsection{CONCLUSION}

Our global findings so far show that there are two groups of states, the EU and the BRICS, that matter in global environmental politics and related issues, like energy, climate change, health and ocean governance. While the first group has played the role of leader in many international law-making initiatives under the UN auspices, the latter lags behind both for social and environmental indexes. As a consequence, their position in Figure 12.5 may also bring some insights about their behaviour and their respective willingness and capacity to comply with these same initiatives. Furthermore, it is also shown that even inside these two groups there are countries much better placed than the others, notably China in the BRICS. This comes as no surprise, but it also shows that China has to make a political choice to stay in a group she does not totally belong to. The USA and Canada are key players in global governance issues, so their position in Figure 12.5 may contribute to understanding their respective diplomatic strategies. Indeed since the USA and Canada rank high in terms of development and have rather low or medium environmental scores, they are comparable to very few countries of our set.

Several countries in northern Europe (including Denmark, Sweden, Ireland, Germany) have good scores on each index separately, which translates into a high ranking in all three partial orders $\mathbf{P 2}$ (development), P3 (environment) and P5 (development and environment). The mixed results of the

\footnotetext{
${ }^{169}$ As long as they are not weighted in the aggregation process as it is the case in CCPI (See Sec.12.2).

${ }^{170}$ hdr.undp.org/en/content/income-gini-coefficient. Accessed on September 19, 2016. The top ten countries in the GINI rank were in 2013: Norway, Australia, Switzerland, Netherlands, USA, Germany, New Zealand, Canada, Singapore and Denmark.

${ }^{171} \mathrm{He}$ found that inequality tended to decrease with robust economic growth in the 1950's. Then he had a lot of criticism afterwards because he did not consider public policy choices in his economic analysis.

172 According to the World Bank Development Report 2014: "more than 20 percent of the population in developing countries live on less than $\$ 1.25$ a day, more than 50 percent on less than $\$ 2,50$ a day and nearly 75 percent on $\$ 4$ a day.
} 
Netherlands on environmental performance - especially on the climate change index CCPI (see Tab. 12.2) - also place it in the group of countries comparable with very few other countries. In 2013 the BRICS have the lowest scores on almost all indicators, a situation which will be interesting to follow the evolution over the years. Note, however, that the approach by partially order sets allows only monitoring the relative positioning of the country with respect to each other. The absolute improvement (resp. deterioration) of a given development or environmental performance can be masked by the simultaneous improvement (resp. degradation) of the other countries' performance. However, we insist that the results presented in this study are conditioned by the initial choice of indexes, namely the three environmental indexes EPI (Yale University et al., USA), CCPI (Germanwatch, Germany) and CLIMI (Smith School of Enterprise and the Environment, UK), and two development indexes, GDP per capita (World Bank) and the HDI (UNDP).

From a methodological point of view it is also clear that a responsible use of indicators requires a critical analysis of at least how they are developed, of the data sources and reliability, and of the meaning attributed to these aggregated indicators. In doing so it is tempting to go along with the opinion Dalal-Clayton and Bass (2002) when they write that (p.159) "a typical set of indicators is a mess of incompatible measurements: pollution in milligrams per litre, ecosystems conversion in hectares, species diversity in species numbers, genetic distance and population change, and so on. Combining such different indicators mixes apples and oranges." However how to assess the status and evolution trends of such complex systems as the environment, or the socio-ecosystems, if not by having recourse to indicators, if any valued at several spatial and temporal scales or governance levels? It seems that we have no alternative today if we adhere, however, beforehand to the idea that the measurement and comparison are useful, or that the production of evidence can assist in the design of public policies and regulations better adapted to the context of their deployment and more likely to lead to the achievement of the objectives for which they were negotiated and designed.

More generally, a broad field of study that combines mathematical and political analysis deserves to be explored in the extension of this first study. The use of indexes becomes a practice increasingly common in many policy areas, environmental issues are no exception (Surminski and Williamson, 2014). Indeed, a growing number of countries is using environmental indexes (e.g. the EPI has been adopted and developed by China to evaluate its green growth priorities and policy implementations, and India launched an Environmental Sustainability Index at the state level; Hsu et al., 2016). The analysis of indicators tends to trigger the introduction of new measures to improve a particular situation in a specific field. As such the composition of a variety of indicators followed by the analysis of the comparability of countries can be useful in making international or national decision, or even for the involvement of a growing number of state or non-state actors in solving societal or environmental issues. Particularly for the achievement of the Sustainability Development Goals ${ }^{173}$, the possibility to consider a broad spectrum of indicators as proposed in this study is an additional mathematical and representation tool to use for a comprehensive analysis of sustainable development.

Acknowledgements. This study is a contibution (PM and CL) to the GEMA project "Gouvernance Environnementale: Modélisation et Analyse" funded by CNRS (Défi interdisciplinaire : "InFIniti » InterFaces Interdisciplinaires Numérique et Théorique).

\footnotetext{
${ }^{173}$ See the Sustainable Development Knowledge Platform at https://sustainabledevelopment.un.org/ (accessed 20 July, 2018)
} 


\section{REFERENCES}

Alkire S (2010) Human development: definitions, critiques and related concepts. OPHI Working Papers 36, University of Oxford, Oxford. http://ophi.org.uk/human-development-definitionscritiques-and-related-concepts/ Accessed 30 Nov 2017

Bartelmus P (2014) What's Beyond GDP? Human Dimensions, May 2014, 4:8-12. http://www.ihdp.unu.edu/docs/Publications/Secretariat/Update-Dimensions/Dimensions\%2012014\%20Beyond\%20GDP.pdf Accessed 30 Nov 2017

Boulet R, Barros-Platiau AF, Mazzega P (2016a) 35 years of multilateral environmental agreements ratification: a network analysis. Artificial Intelligence and Law 24(2):133-148. DOI 10.1007/s10506-016-9180-7

Boulet R, Barros-Platiau AF, Mazzega P (2016b) Country communities underlying the ratification of environmental agreements. Submitted.

Burck J, Hermwille L, Krings L (2012) The climate change performance index - results 2013. Germanwatch - Bonn Office and CAN Climate Action Network Europe Brussels, Bonn. https://germanwatch.org/en/5698 Accessed 30 Nov 2017

Burck J, Hermwille L, Bals C (2015) The climate change performance index - background and methodology. Germanwatch - Bonn Office and CAN Climate Action Network Europe Brussels, Bonn. https://germanwatch.org/en/ccpi_bame Accessed 30 Nov 2017

Dalal-Clayton B, Bass S (2002) Sustainable development strategies: a resource book. Earthscan, Routledge, London

Dasgupta P (2014) Health and Nature in Inclusive Wealth. Human Dimensions May 2014, 4:14-18. http://www.ihdp.unu.edu/docs/Publications/Secretariat/Update-Dimensions/Dimensions\%2012014\%20Beyond\%20GDP.pdf Accessed 30 Nov 2017

Downie C (2015) Global energy governance: do the BRICS have the energy to drive reform? International Affairs 91(4):799-812. DOI: 10.1111/1468-2346.12338

Duraiappah A, Fernandes C (2014) GDP Reexamined. Human Dimensions, May 2014(4), 33-36. http://www.ihdp.unu.edu/docs/Publications/Secretariat/Update-Dimensions/Dimensions\%2012014\%20Beyond\%20GDP.pdf Accessed 30 Nov 2017

Fehling M, Nelson BD, Venkatapuram S (2013) Limitations of the millennium development goals: a literature review. Global Public Health 8 (10):1109-1122. doi: 10.1080/17441692.2013.845676

Ge M., Johannes Friedrich J, Damassa T (2014) 6 Graphs explain the World's top 10 emitters. World Resources Institute - WRI Global Climate Program . http://www.wri.org/blog/2014/11/6-graphsexplain-world\%E2\%80\%99s-top-10-emitters Accessed 30 Nov 2017

Hammond AL, Adriaanse A, Rodenburg E, Bryant D, Woodward R (1995) Environmental indicators : a systematic approach to measuring and reporting on environmental policy performance in the context of sustainable development. World Resources Institute, Washington DC. http://pdf.wri.org/environmentalindicators_bw.pdf Accessed 30 Nov 2017

Hsu A et al (2016) 2016 Environmental Performance Index. Yale University, New Haven CT. https://issuu.com/rodrigovelasquezangel/docs/epi2016_final_report Accessed 30 Nov 2017

Hsu A, Johnson L, Lloyd A (2013) Measuring progress: a practical guide from the developers of the Environmental Performance Index. Yale Center for Environmental Law and Policy, New Haven CT. http://archive.epi.yale.edu/files/ycelp measuring progress manual.pdf Accessed 30 Nov 2017

ICSU ISSC (2015) Review of the Sustainable Development Goals: the science perspective. International Council for Science (ICSU), Paris. https://www.icsu.org/cms/2017/05/SDGReport.pdf Accessed 30 Nov 2017

Jones GA, Warner KJ (2016) The $21^{\text {st }}$ century population-energy-climate nexus. Energy Policy 93:206-212. http://dx.doi.org/10.1016/j.enpol.2016.02.044 
Kirton J, Kokotsis E (2016) The Global Governance of Climate Change. G7, G20 and UN Leadership. Routledge, Abingdon

Kovacevic M (2010) Measurement of inequality in human development - a review. UNDP - Human Dev. Rep., Res. Paper 2010/35, UNDP, New York. http://hdr.undp.org/en/content/measurementinequality-human-development-\%E2\%80\%93-review Accessed 30 Nov 2017

Lajaunie C, Mazzega P (2017) Transmission, circulation et persistance des enjeux de santé dans les conventions internationales liées à la Biodiversité et Conventions de Rio. In: Maljean-Dubois S (ed) Diffusion de normes et circulations d'acteurs dans la gouvernance internationale de l'environnement, Confluence des Droits, Aix en Provence, p 61-80. http://dice.univamu.fr/sites/dice.univ-amu.fr/files/public/ouvrage circulex 2017.pdf Accessed 30 Nov 2017

Meadows D (1998) Indicators and information systems for sustainable development. The Sustainability Institute, Hartland Four Corners. http://www.iisd.org/pdf/s ind 2.pdf Accessed 30 Nov 2017

Monebhurrun N (2016) La fonction du développement dans le droit international des investissements. L'Harmattan, Paris

Ness B, Urbel-Piirsalu E, Anderberg S, Olsson L (2007) Categorising tools for sustainability assessment. Ecological Economics 60(3):498-508. https://doi.org/10.1016/j.ecolecon.2006.07.023

Rist G (2001) Le développement. Histoire d'une croyance occidentale, 2ème éd.. Presses de Sciences Po, Paris

Saari DG (2001) Decisions and elections. Explaining the unexpected. Cambridge University Press, Cambridge

Shambaugh D (2016) China's Future. Polity Press, Cambridge

Schröder BSW (2003) Ordered sets. An introduction. Birkhäuser Boston Inc., Boston

Steves F, Teytelboym A (2013) Political Economy of Climate Change Policy. Working paper 13-06, Smith School of Enterprise and the Environment, Oxford. http://www.smithschool.ox.ac.uk/publications/wpapers/workingpaper13-06.pdf Accessed 30 Nov 2017

Surminski S, Williamson A (2014) Policy indexes as tools for decision makers: the case of climate policy. Global Policy 5(3):275-285. doi: 10.1111/1758-5899.12121

Trotter W. T. (1992) Combinatorics and partially ordered sets. Dimension theory. Johns Hopkins Series in the Mathematical Sciences. Johns Hopkins University Press, Baltimore

United Nations (2016) The sustainable development goals report 2016. UN publication issued by the Department of Economic and Social Affairs (DESA), New York. https://unstats.un.org/sdgs/report/2016/ Accessed 30 Nov 2017

UNCED (1992) United Nations Conference on Environment \& Development - Agenda 21. Rio de Janeiro. https://sustainabledevelopment.un.org/outcomedocuments/agenda21 Accessed 30 Nov 2017

UNDP (1990) Human development report 1990: Concept and measurement of human development. United Nations Development Programme. Oxford University Press, New York. http://hdr.undp.org/en/reports/global/hdr1990 Accessed 30 Nov 2017

Viola E, Basso L (2016) Wandering decarbonization: the BRIC countries as conservative climate powers. Rev. Bras. Polít. Int. 59(1): e001. DOI: http://dx.doi.org/10.1590/0034-7329201600101.

Vogler J (2011) The challenge of the environment, energy and climate change. In: Hill C, Smith M (eds), International Relations and the European Union 2d edition. Oxford Univ. Press, Oxford, $\mathrm{p}$ 349-379

Zwicker WS (2016) Introduction to the theory of voting. In: Brandt F, Conitzer V, Endriss U, Lang J, Procaccia AD (eds), Handbook of Computational Social Choice. Cambridge University Press, Cambridge, p 23-56 